\title{
Prevalence and associated factors of malnutrition among children under-five years in Sindh, Pakistan: a cross-sectional study
}

Gul Nawaz Khan', Ali Turab', Mohammad Imran Khan², Arjumand Rizvi', Fariha Shaheen', Asmat Ullah',

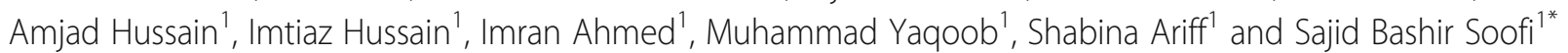

\begin{abstract}
Background: Globally, malnutrition accounts for at least half of all childhood deaths. Managing malnutrition in the community settings involves identifying malnutrition using a universally validated screening tool and implementing appropriate interventions according to the degree of malnutrition. The aim of this study was to estimate prevalence and associated factors that result in malnutrition among children under-five years of age in Thatta and Sujawal districts in Sindh province, Pakistan.
\end{abstract}

Methods: A cross-sectional survey was conducted between May and August 2014. A total of 3964 children underfive years were enrolled in the study. The WHO growth standards height-for-age Z-scores (HAZ), weight-for-height Z-scores (WHZ) and weight-for-age Z-scores (WAZ) were used to measure stunting, wasting and underweight. A structured questionnaire was used to collect data on socioeconomic conditions, family size, maternal education, parity and child morbidity. Multivariable logistic regression was used to determine the risk factors for malnutrition.

Results: The prevalence of stunting, wasting and underweight were 48.2\% (95\% Cl: 47.1-50.3), 16.2\% (95\% Cl: $15.5-17$. 9), and 39.5\% (95\% Cl: 38.4-41.5), respectively. Stunting was slightly higher (51\%) in boys than in girls (45\%) ( $p<0.001)$. The proportion of wasting $(p=0.039)$ and underweight $(p=0.206)$ was not significantly different between boys and girls. Fifty percent children in the poorest households were stunted as compared to $42 \%$ in the wealthiest households. Children in the poorest households were two times more likely to be wasted (20.6\%) than children in the wealthiest households (10.3\%) (OR 2.33, Cl 1.69-3.21, $p<0.001)$. A similar relationship was observed between household wealth and underweight in children (43.8\% in poorest and $28.8 \%$ in wealthiest households (OR 2.18, Cl 1.72-2.77, $p<0.001)$. Household wealth was significantly associated with stunting, wasting and underweight. Diarrhea was associated with underweight. Factors such as mother's education, parity and family size were not associated with malnutrition in our study area.

Conclusions: The findings of our study revealed that malnutrition was widespread among the children underfive years of age. The food/nutrient based interventions together with improved hygiene practices and household wealth should be targeted to improve malnutrition situation in the study area and in the country.

Keywords: Malnutrition, Prevalence, Children, Stunting, Wasting, Underweight

\footnotetext{
* Correspondence: sajid.soofi@aku.edu

'Department of Paediatrics and Child Health, Aga Khan University, Karachi,

Pakistan

Full list of author information is available at the end of the article
} 


\section{Background}

Globally in 2014, an estimated 159 million children under-five years were stunted, 95 million were underweight and 50 million were wasted [1]. Malnutrition accounts for at least half of all childhood deaths worldwide $[2,3]$. Despite the economic development, childhood malnutrition still remains a major public health problem in developing countries $[2,4,5]$. Contributing factors in childhood malnutrition are intra-uterine growth retardation, low birth weight, inadequate exclusive breast feeding, inappropriate complementary feeding, maternal education, low nutritional knowledge, insufficient energy and micronutrient intake, birth spacing, parity, socioeconomic background, food availability, housing, poor sanitation, health services, vaccination and infectious diseases [5-15].

The Islamic Republic of Pakistan is among the countries in the world with the highest rates of child malnutrition (Stunting 44\%, Wasting 15\% \& underweight 31\%) and its progress in child nutrition and health remained slower than in other South Asian countries [16-18]. The data obtained from the National Nutrition Survey (NNS) 2011 indicated little change over the last decade in terms of childhood nutrition indicators. Among children under-five, 44\% were stunted in 2011 as compared to $41 \%$ in the 2001. Fifteen-percent were wasted compared to $14 \%$ in 2001 and $31 \%$ were underweight, which has not changed since 2001. The malnutrition rates were relatively lower in urban areas compared to rural areas in Pakistan [19]. This paper presents the results of baseline data of a large project on effectiveness of food/nutrient based interventions to prevent stunting among children under-five years in districts Thatta and Sujawal, Sindh province, Pakistan.

\section{Methods}

\section{Study design}

A cross-sectional survey design was used to collect data between May and August 2014. The survey was designed to provide baseline information on a representative sample of households in the study area.

\section{Study setting}

The study was conducted in 29 Union Councils (UCs) of Thatta and Sujawal districts in Sindh, Pakistan. These districts are located in the southern part of the Sindh province. They are administratively subdivided into 9 Talukas and 55 UCs with a population of 1.5 million.

According to the 2014 Multiple Indicators Cluster Survey (MICS) conducted in Sindh, more than $88 \%$ of the population in Thatta and Sujawal have access to improved sources of drinking water, $68 \%$ have access to electricity, and $31 \%$ of households own agriculture land. Furthermore, few of the households have finished floors
(35\%), roofing (36\%) and walls (40\%). Individuals in the poorest wealth quintiles own more than $50 \%$ of households, while only $3 \%$ of households belong to individuals in the richest wealth quintiles [20].

\section{Sample size}

Sample size was calculated using comparison of two sequential surveys approach to assess the impact of intervention over time as discussed in Micronutrient Initiative (MI) and United States Center for Disease Control (CDC) manual [21]. Sample size calculation considered the prevalence of stunting in Sindh province at 49\% (NNS 2011) and design effect of 2 . Total sample size required was 3964 per survey to detect $10 \%$ difference with $80 \%$ power and $5 \%$ level of significance.

\section{Sampling methodology}

A two-staged cluster sampling technique was used to select households for interviews. In the first stage, sample size was divided in 29 UCs using a Proportion to Population Size (PPS) design. In the second stage,

Table 1 Socio-demographic characteristics of the sample population

\begin{tabular}{|c|c|c|}
\hline Indicators & $n$ & Percent \\
\hline \multicolumn{3}{|l|}{ Gender } \\
\hline Male & 2025 & 51.1 \\
\hline Female & 1939 & 48.9 \\
\hline Age in months (Mean $\pm S D$ ) & $22.81 \pm 15.23$ & \\
\hline$<6$ months & 602 & 15.2 \\
\hline 6-11 months & 645 & 16.3 \\
\hline 12-23 months & 828 & 20.9 \\
\hline 24-35 months & 1041 & 26.3 \\
\hline 36-47 months & 529 & 13.3 \\
\hline 48-59 months & 319 & 8 \\
\hline \multicolumn{3}{|l|}{ Mother's education } \\
\hline No formal education & 3439 & 87.9 \\
\hline Primary & 348 & 8.9 \\
\hline Secondary/Higher & 125 & 3.2 \\
\hline Parity & $1.49 \pm 0.73$ & \\
\hline 1 & 2349 & 59.8 \\
\hline 2 & 1237 & 31.5 \\
\hline 3 & 278 & 7.1 \\
\hline$>4$ & 66 & 1.7 \\
\hline Family size & $6.7 \pm 2.8$ & \\
\hline $1-5$ & 1552 & 39.2 \\
\hline $6-10$ & 2053 & 51.8 \\
\hline$>10$ & 359 & 9.1 \\
\hline
\end{tabular}


Table 2 Prevalence of stunting in children under-five years of age

\begin{tabular}{|c|c|c|c|c|}
\hline & \multirow[t]{2}{*}{$N$} & \multicolumn{2}{|l|}{ Stunted } & \multirow{2}{*}{$\begin{array}{l}\text { Mean Z- } \\
\text { score (SD) }\end{array}$} \\
\hline & & (<-2 z-score) & $(<-3$ z-score $)$ & \\
\hline All children & 3903 & $48.2(47.1-50.3)$ & $23.9(22.6-25.3)$ & $-1.92(1.53)$ \\
\hline \multicolumn{5}{|l|}{ Sex } \\
\hline Boys & 1993 & $51.3(49.4-53.8)$ & $25.5(23.6-27.4)$ & $-1.99(1.55)$ \\
\hline Girls & 1910 & $45.1(43.4-47.8)$ & $22.3(20.4-24.2)$ & $-1.83(1.51)$ \\
\hline \multicolumn{5}{|l|}{ Age group } \\
\hline $0-5$ months & 588 & $21.9(18.7-25.4)$ & $9.7(7.3-12.1)$ & $-0.97(1.58)$ \\
\hline 6-11 months & 639 & $34.3(31.0-38.4)$ & $14.9(12.1-17.6)$ & $-1.37(1.66)$ \\
\hline $12-23$ months & 815 & $56.2(53.4-60.2)$ & $27.9(24.7-30.9)$ & $-2.15(1.4)$ \\
\hline 24-35 months & 1027 & $59.9(57.4-63.4)$ & $32.9(30.0-35.8)$ & $-2.38(1.34)$ \\
\hline 36-47 months & 519 & $62.6(59.0-67.3)$ & $28.7(24.8-32.6)$ & $-2.35(1.37)$ \\
\hline 48-59 months & 315 & $43.5(38.3-49.3)$ & $21.6(17.0-26.1)$ & $-1.97(1.25)$ \\
\hline
\end{tabular}

villages and households with children under-five years were randomly selected for interview.

\section{Data collection}

A structured household survey questionnaire was used to collect data through face-to-face interviews from mothers. The information collected included socio-economic and demographic characteristics, food insecurity, morbidity and child anthropometric measurements. Questionnaire was tested during the field testing and changes were incorporated accordingly. The questionnaire was initially designed in English, translated in Sindhi by senior project team member and then back-translated to English by an independent person to check for inconsistencies. Weight, length or height and mid-upper arm circumference (MUAC) were measured using standard anthropometric methods. Seca-874 was used for weight measurement, seca-213 used for height measurement, seca-210 measuring mat for measuring the length and MUAC tape for children with three colours of thresholds at red to $115 \mathrm{~mm}$, yellow 115-125 mm and green from $125 \mathrm{~mm}$ was used. We measured length for children $<24$ months and height for children 24-59 months according to WHO standards [22]. The measurements were obtained by two trained anthropometrists. The date of birth was reported by the mother and verified by birth certificates and vaccination cards. Sixteen enumerators, 4 team leaders, 2 desk editors and 2 field supervisors were hired, trained and involved in baseline data collection.

\section{Statistical analysis}

Three anthropometric indicators were constructed on height-for-age (HAZ), weight-for age (WAZ) and weightfor-height (WHZ) in the form of z-scores using WHO Anthro 2006 software. Each z-score depicts the deviation from the median height or weight of a child of the same age and sex in the reference population. Stunting was defined as height-for- age $(Z$-score $<-2)$, wasting as weight-for-height $(Z$-score $<-2)$, and underweight as weight-for-age (Z-score $<-2)$ using child growth standards published by the World Health Organization (WHO) in 2006 [22]. WHO Anthro 2006 software by default flagged missing data and implausibly high or low observations. Hence total $2.9 \%$ of the observations were eliminated due to flagging.

The study population's characteristics were summarized using means with standard deviations (SD) for the continuous variables and percentages for the categorical variables. Confidence intervals were also reported for inference.

Predictors of childhood malnutrition (stunting, wasting, under-weight and all three) were investigated using logistic regression analysis. A range of child, maternal

Table 3 Prevalence of wasting in children under-five years of age

\begin{tabular}{|c|c|c|c|c|c|c|}
\hline & \multirow[t]{2}{*}{$N$} & \multicolumn{2}{|l|}{ Wasted } & \multicolumn{2}{|l|}{ Overweight } & \multirow{2}{*}{$\begin{array}{l}\text { Mean Z- } \\
\text { score (SD) }\end{array}$} \\
\hline & & $<-2 \mathrm{SD}$ & $<-3 \mathrm{SD}$ & $>2 S D$ & $>3 \mathrm{SD}$ & \\
\hline All children & 3906 & $16.2(15.5-17.9)$ & $5.4(5.0-6.5)$ & $2.5(2.1-3.2)$ & $0.6(0.5-1.0)$ & $-0.76(1.34)$ \\
\hline \multicolumn{7}{|l|}{ Sex } \\
\hline Boys & 1997 & $16.8(15.9-19.2)$ & $5.5(5.1-7.2)$ & $2.7(2.1-3.5)$ & $0.8(0.4-1.2)$ & $-0.79(1.37)$ \\
\hline Girls & 1909 & $15.5(14.1-17.4)$ & $5.2(4.5-6.5)$ & $2.3(1.8-3.2)$ & $0.5(0.3-1.1)$ & $-0.74(1.32)$ \\
\hline \multicolumn{7}{|l|}{ Age group } \\
\hline $0-5$ months & 581 & $11.2(9.3-14.5)$ & $4.3(3.3-6.9)$ & $8.1(6.2-10.7)$ & $1.9(1.1-3.6)$ & $-0.23(1.56)$ \\
\hline 6-11 months & 638 & $16.8(14.3-20.1)$ & $4.7(3.5-7.0)$ & $3.1(2.0-4.8)$ & $0.6(0.2-1.7)$ & $-0.67(1.39)$ \\
\hline $12-23$ months & 822 & 15.7 (13.9-19.0) & $5.2(4.0-7.1)$ & $1.8(0.9-2.9)$ & $0.6(0.1-1.3)$ & $-0.85(1.26)$ \\
\hline 24-35 months & 1032 & $20.8(18.5-23.5)$ & $7.1(5.6-8.7)$ & $0.7(0.1-1.2)$ & $0.1(0.09-0.3)$ & $-1.03(1.26)$ \\
\hline 36-47 months & 518 & $14.7(12.2-18.4)$ & $5.6(4.2-8.4)$ & $1.4(0.3-2.3)$ & $0.4(0.24-1.5)$ & $-0.79(1.27)$ \\
\hline 48-59 months & 315 & $12.4(9.5-16.9)$ & $3.2(1.7-5.9)$ & $0.6(0.1-2.0)$ & $0.3(0.24-1.5)$ & $-0.79(1.09)$ \\
\hline
\end{tabular}


Table 4 Prevalence of underweight in children under 5 years of age

\begin{tabular}{lllll}
\hline & $N$ & \multicolumn{2}{l}{ Underweight } & \multirow{2}{*}{$\begin{array}{l}\text { Mean Z- } \\
\text { score (SD) }\end{array}$} \\
\cline { 3 - 4 } & & $(<-2$ SD $)$ & $(<-3$ SD $)$ & \\
\hline All children & 3939 & $39.5(38.4-41.5)$ & $14.6(13.5-15.7)$ & $-1.68(1.31)$ \\
Sex & & & & \\
\multicolumn{1}{c}{ Boys } & 2011 & $40.2(38.5-42.8)$ & $15.3(13.7-16.8)$ & $-1.73(1.31)$ \\
Girls & 1928 & $38.7(37.1-41.4)$ & $14.0(12.4-15.5)$ & $-1.64(1.32)$ \\
Age group & & & & \\
0-5 months & 596 & $21.6(18.5-25.1)$ & $9.4(7.1-11.7)$ & $-0.96(1.47)$ \\
6-11 months & 642 & $28.3(25.0-32.0)$ & $11.4(8.9-13.8)$ & $-1.35(1.46)$ \\
12-23 months & 822 & $41.0(38.2-44.9)$ & $14.2(11.8-16.6)$ & $-1.74(1.23)$ \\
24-35 months & 1035 & $51.6(49.2-55.3)$ & $18.7(16.4-21.1)$ & $-2.06(1.11)$ \\
36-47 months & 527 & $48.4(44.9-53.4)$ & $19.2(15.8-22.5)$ & $-2.02(1.16)$ \\
$48-59$ months & 317 & $37.5(32.5-43.2)$ & $11.0(7.6-14.5)$ & $-1.77(1)$ \\
\hline
\end{tabular}

and household level factors were included in the modelling such as child age and gender, maternal education and parity, family size and wealth index. Wealth index is a composite score constructed with broad range of socioeconomic indicators including household construction material, source of drinking water and sanitation facilities, household utilities and assets using principal component analysis. This score further divided in 5 equal categories comprising $20 \%$ of the data in each category [23].

Univariate analysis was conducted to determine independent effect of each predictor on outcomes. Then all predictors were included in multivariate analysis to investigate net effect of each predictor on outcomes adjusting for all other factors in the model. Adjusted OR were calculated to study the predictive power of independent study variables in relation to childhood malnutrition. All statistical analyses were performed using SPSS version 15.0 with the statistical significance set at a $p$ value $\leq 0.05$.

\section{Results}

\section{Socio-demographic characteristics}

Socio-demographic characteristics of the sampled children, their mothers and households are presented in Table 1. Mother's educational levels were relatively low and $88 \%$ of mothers were not formally educated. We collected data for 3964 children, among them $51 \%$ were males and $49 \%$ were females. Fifty-two percent children were under the age of two years, while $48 \%$ children were between age of $2-5$ years. About $40 \%$ of children had two or more siblings in the selected households. More than half of households had 6-10 family members, while $9 \%$ had more than ten family members.

\section{Prevalence of stunting}

The prevalence of stunting in the study sample was $48 \%$, and was slightly higher $(51 \%)$ in boys than in girls (45\%). Similarly, severe stunting rates were slightly higher in boys (25.5\%) than in girls (22.3\%). Stunting rates gradually increased from $22 \%$ in children $<5$ months old to $62.6 \%$ in children $36-47$ months old, however it reduced in children 48 to 59 months (43.5\%) [Table 2].

\section{Prevalence of wasting}

The prevalence of wasting in the study area was $16.2 \%$. Proportion of wasting among boys and girls was not prominent. Wasting increased with age, peaking at $20.8 \%$ among children in 24-35 months of age. Only $2.5 \%$ children were overweight [Table 3].

\section{Prevalence of underweight}

Overall, 39.5\% of children under the age of five years were underweight. Prevalence of underweight for both sexes was almost same. The rates of underweight increased with age, peaking at $51.6 \%$ among children in $24-35$ months of

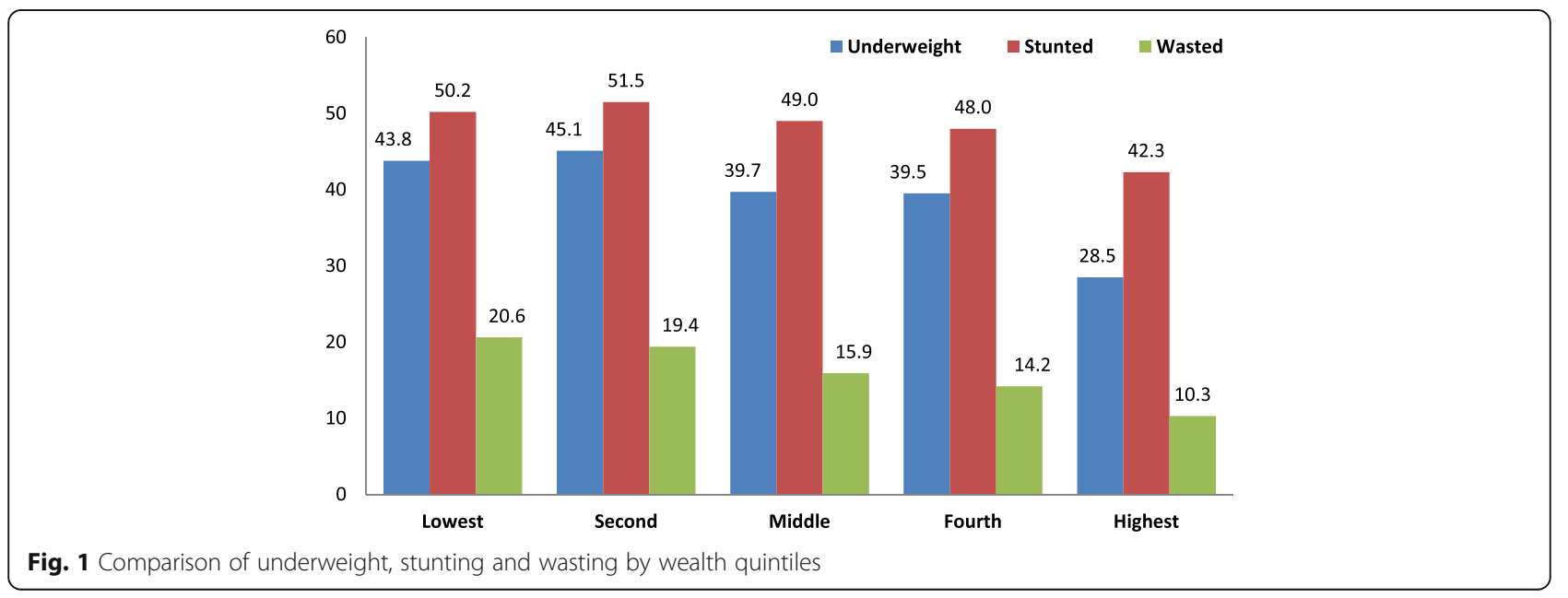


Table 5 Results of multivariable logistic regression analysis showing determinants of malnutrition

\begin{tabular}{|c|c|c|c|c|c|c|c|c|}
\hline \multirow[t]{2}{*}{ Variables } & \multicolumn{2}{|l|}{ Stunting } & \multicolumn{2}{|l|}{ Wasting } & \multicolumn{2}{|l|}{ Under-weight } & \multicolumn{2}{|c|}{ All three outcomes } \\
\hline & OR $(95 \% \mathrm{Cl})$ & $p$-value & OR $(95 \% \mathrm{Cl})$ & $p$-value & OR $(95 \% \mathrm{Cl})$ & $p$-value & $\mathrm{OR}(95 \% \mathrm{Cl})$ & $p$-value \\
\hline \multicolumn{9}{|l|}{ Gender } \\
\hline Boys & $1.30(1.14-1.49)$ & $<0.0001$ & $1.20(1.01-1.43)$ & 0.039 & $1.09(0.95-1.25)$ & 0.206 & $1.29(1.02-1.65)$ & 0.037 \\
\hline Girls & Ref. & & & & & & & \\
\hline \multicolumn{9}{|l|}{ Age } \\
\hline$<6$ months & Ref. & & & & & & & \\
\hline 6-11 months & $1.93(1.49-2.51)$ & $<0.0001$ & $1.43(1.03-1.99)$ & 0.033 & $1.39(1.06-1.81)$ & $<0.0001$ & $3.17(1.72-5.85)$ & $<0.0001$ \\
\hline $12-23$ months & $4.93(3.86-6.30)$ & $<0.0001$ & $1.41(1.03-1.94)$ & 0.032 & $2.64(2.07-3.38)$ & $<0.0001$ & $4.99(2.79-8.90)$ & $<0.0001$ \\
\hline 24-35 months & $5.66(4.45-7.20)$ & $<0.0001$ & $1.93(1.43-2.60)$ & 0.000 & $4.30(3.39-5.47)$ & $<0.0001$ & $4.23(2.37-7.53)$ & $<0.0001$ \\
\hline $36-47$ months & $6.90(5.21-9.13)$ & $<0.0001$ & $1.30(0.91-1.87)$ & 0.151 & $4.17(3.16-5.49)$ & $<0.0001$ & $3.96(2.11-7.43)$ & $<0.0001$ \\
\hline 48-59 months & $2.99(2.19-4.10)$ & $<0.0001$ & $1.15(0.75-1.77)$ & 0.516 & $2.51(1.82-3.45)$ & $<0.0001$ & $2.30(1.09-4.85)$ & 0.029 \\
\hline \multicolumn{9}{|l|}{ Mother's education } \\
\hline No formal education & $0.93(0.62-1.40)$ & 0.730 & $0.94(0.53-1.70)$ & 0.847 & $0.72(0.48-1.09)$ & 0.121 & $0.97(0.42-2.22)$ & 0.936 \\
\hline Primary & $0.74(0.47-1.15)$ & 0.180 & $0.71(0.37-1.36)$ & 0.300 & $0.55(0.35-0.86)$ & 0.010 & $0.61(0.23-1.57)$ & 0.302 \\
\hline Secondary /Higher & Ref. & & & & & & & \\
\hline \multicolumn{9}{|l|}{ Parity } \\
\hline 1 & Ref. & & & & & & & \\
\hline 2 & $1.07(0.92-1.26)$ & 0.378 & $1.01(0.83-1.23)$ & 0.936 & $1.19(1.02-1.40)$ & 0.029 & $0.97(0.73-1.28)$ & 0.823 \\
\hline 3 & $1.24(0.93-1.65)$ & 0.137 & $1.00(0.69-1.45)$ & 0.987 & $1.41(1.06-1.88)$ & 0.018 & $1.23(0.75-2.01)$ & 0.412 \\
\hline$>4$ & $1.41(0.81-2.46)$ & 0.221 & $0.87(0.40-1.91)$ & 0.733 & $1.16(0.65-2.06)$ & 0.623 & $0.97(0.33-2.87)$ & 0.961 \\
\hline \multicolumn{9}{|l|}{ Family size } \\
\hline $1-5$ & Ref. & & & & & & & \\
\hline $6-10$ & $1.04(0.90-1.20)$ & 0.594 & $0.99(0.82-1.19)$ & 0.883 & $0.97(0.84-1.12)$ & 0.663 & $0.95(0.74-1.23)$ & 0.725 \\
\hline$>10$ & $1.02(0.79-1.33)$ & 0.862 & $1.16(0.83-1.62)$ & 0.391 & $1.00(0.77-1.30)$ & 0.987 & $1.13(0.72-1.80)$ & 0.590 \\
\hline \multicolumn{9}{|l|}{ Wealth quintiles } \\
\hline Lowest & $1.49(1.18-1.88)$ & 0.001 & $2.33(1.69-3.21)$ & $<0.0001$ & $2.18(1.72-2.77)$ & $<0.0001$ & $2.31(1.47-3.64)$ & $<0.0001$ \\
\hline Second & $1.52(1.20-1.91)$ & 0.000 & $2.01(1.45-2.77)$ & $<0.0001$ & $2.11(1.66-2.68)$ & $<0.0001$ & $2.07(1.31-3.27)$ & 0.002 \\
\hline Middle & 1.37 (1.09-1.73) & 0.006 & $1.74(1.26-2.41)$ & $<0.0001$ & $1.73(1.36-2.19)$ & $<0.0001$ & $1.82(1.15-2.88)$ & 0.010 \\
\hline Fourth & $1.30(1.04-1.62)$ & 0.022 & $1.40(1.01-1.94)$ & $<0.0001$ & $1.67(1.32-2.10)$ & $<0.0001$ & $1.45(0.91-2.31)$ & 0.115 \\
\hline Highest & Ref. & & & & & & & \\
\hline \multicolumn{9}{|l|}{ Morbidity } \\
\hline Diarrhea & $1.13(0.97-1.33)$ & 0.124 & $1.18(0.97-1.45)$ & 0.099 & $1.36(1.16-1.59)$ & $<0.0001$ & $1.27(0.97-1.67)$ & 0.084 \\
\hline ARI & $0.99(0.82-1.19)$ & 0.883 & $0.94(0.74-1.19)$ & 0.617 & $0.98(0.82-1.19)$ & 0.871 & $0.84(0.60-1.17)$ & 0.306 \\
\hline
\end{tabular}

age, and then dropped to $37.5 \%$ among children in $48-59$ months of age [Table 4].

\section{Association of malnutrition with wealth quintiles}

Figure 1 presented comparison of underweight, stunting and wasting rates by wealth quintiles. The prevalence of underweight, stunting and wasting was higher in children of poorest households than in children of wealthiest households. Fifty percent children in the poorest households were stunted compared to $42 \%$ in the wealthiest households. Children in the poorest households were two times more likely to be wasted $(20.6 \%)$ compared to children in the wealthiest households (10.3\%). A similar relationship was observed between household wealth and underweight in children $(43.8 \%$ in poorest and $28.8 \%$ in wealthiest households) in the study area.

Multiple malnutrition (stunting, wasting and underweight) was higher in boys than girls. Children aged between 12 and 23 months were in more risk for being stunted and underweight than in other age groups [Tables 2 and 4]. 


\section{Determinants associated with malnutrition}

Determinants related to stunting, wasting and underweight presented in Table 5. Determinants such as mother's education, parity and family size was not associated with stunting, wasting and underweight; while gender, age and wealth quintiles was associated with malnutrition. Diarrhea was associated with underweight. The p-value of stunting in boys was highly significant $<0.0001$ relative to girls, but it was not significant for wasting and underweight in the study area.

\section{Discussion}

This study was conducted to provide baseline results for a large trial for the effectiveness of food/nutrient based interventions to prevent stunting among children under-five years in Thatta and Sujawal districts of Sindh province, Pakistan. The findings of our study revealed that malnutrition was widespread among the children under-five year old, and has not improved since last two decades [19]. The study data provide critical information on child nutrition, health, household wealth quintiles, family size, parity and food security in the sampled population.

Stunting prevalence found in this study area was $48.2 \%$ and is considered as 'Very High' public health significance according to WHO standards. The prevalence of stunting was slightly higher (51\%) in boys than in girls (45\%). These findings are comparable with national results reported in PDHS 2012-13 [19] and in a metaanalysis for sub-Saharan Africa studies [24].

The rapid increase in stunting between 6 and 24 months of life (from 34 to $56 \%$ ) in the study area is particularly concerning. This is the "window of opportunity" as well to prevent stunting during the pregnancy and the first 2 years of life of the child, cumulating a critical period for intervention of 1000 days. Unfortunately, after two years of age, it is extremely difficult to intervene and catch-up growth, leading to irreversible damages in the development of the child.

The results of our study also revealed that there was a highly significant chance for being of stunted, wasted and underweight in children belonging to the lower quintiles as compared to highest quintiles, and almost similar findings were reported in three studies from Africa [25-27].

Research studies had identified maternal education higher than primary school, as one of the main factors of childhood malnutrition [27-30]. As many women in our study area were illiterate and we anticipate that maternal education had limited implications for inter-household differences in nutrition, and similar finding were reported in a study from Democratic Republic of Congo [31].

Household food insecurity was also positively associated with wasting but not with stunting and underweight in our study area. Food insecurity was associated with higher child undernutrition in Bangladesh, Ethiopia, and Vietnam [32] but not associated with child undernutrition in a study from rural Cambodia [33].

\section{Conclusions}

The findings of our study revealed that malnutrition was widespread among the children under-five years. Household wealth was highly associated with all three forms of nutritional outcomes. To succeed in the reduction of child malnutrition in the study area and in Pakistan, interventions must target short term nutrition supplements and long term economic empowerments of poor communities. Further research is recommended to investigate potential factors associated with child malnutrition, and interventions to improve nutritional status in children under-five years.

\section{Abbreviations}

CDC: Center for Disease Control; Cl: Confidence intervals; ERC: Ethical review committee; HAZ: Height-for-age z-scores; MI: Micronutrient Initiative; MUAC: Mid-upper arm circumference; NBC: National Bio-Ethics Committee; NNS: National Nutrition Survey; OR: Odds ratio; PDHS: Pakistan Demographic Health Survey; PPS: Proportion to Population Size; SD: Standard deviation; UCs: Union Councils; WAZ: Weight-for-age z-scores; WHO: World Health Organization; WHZ: Weight-for-height z-scores

\section{Acknowledgments}

We are grateful to the staff of health department and study participants for their time and contribution. We would like to appreciate all staff of the study for their hard work and support provided by DMU, Aga Khan University, Pakistan.

\section{Funding}

This study was financially supported by World Food Programme (WFP), Pakistan.

Availability of data and materials

Data will be available upon request to corresponding author.

\section{Authors' contributions}

SBS conceptualized the study, its design and analysis plan. SBS, GNK, AT, AU, IH and MY were involved in implementation of the study. GNK wrote first and subsequent drafts, participated in data acquisition and data analysis plan. AR and FS participated in data analysis. AH, IA, AU, SA and GNK involved in data management. MIK and AT edited the manuscript. All authors reviewed and approved the content of the final manuscript.

Competing interests

The authors declare that they have no competing interests.

Consent for publication

Not applicable.

Ethics approval and consent to participate

The study was reviewed and approved by Ethical Review Committee (ERC) of Aga Khan University and National Bio-Ethics Committee (NBC) of Pakistan. Informed written consent was obtained from parents of each study participant to participate in the study and all the data was kept confidential.

\section{Author details}

${ }^{1}$ Department of Paediatrics and Child Health, Aga Khan University, Karachi, Pakistan. ${ }^{2}$ Center of Excellence in Women and Child Health, Aga Khan University, Karachi, Pakistan.

Received: 7 September 2016 Accepted: 18 November 2016 Published online: 24 November 2016 


\section{References}

1. UNICEF/WHO/World Bank. Joint Child Malnutrition Estimates by UNICEF WHO \& World Bank. 2014. http://data.worldbank.org/child-malnutrition.

2. Demissie S, Worku A. Magnitude and factors associated with malnutrition in children 6-59 months of age in Pastoral community of Dollo Ado District, Somali Region, Ethiopia. Sci J Public Health. 2013;1:175-83.

3. Meshram II, Arlappa N, Balakrishna N, Rao KM, Laxmaiah A, Brahmam GNV. Trends in the prevalence of undernutrition, nutrient and food intake and predictors of undernutrition among under five year tribal children in India. Asia Pac J Clin Nutr. 2012;21:568-76.

4. Masibo PK, Makoka D. Trends and determinants of undernutrition among young Kenyan children: Kenya Demographic and Health Survey; 1993, 1998 2003 and 2008-2009. Public Health Nutr. 2012;15:1715-27.

5. Pasricha SR, Biggs BA. Undernutrition among children in South and SouthEast Asia. J Paediatr Child Health. 2010:46:497-503.

6. Jesmin A, Yamamoto SS, Malik AA, Haque A. Prevalence and determinants of chronic malnutrition among preschool children: a cross-sectional study in Dhaka City, Bangladesh. J Health Popul Nutr. 2011;29:494-9.

7. Pruss-Unstun A, Bos R, Gore F, Bartram J. Safer water, better health: costs, benefits and sustainability of interventions to protect and promote health. Geneva: WHO; 2008

8. Lozano R, Naghavi M, Foreman K, Lim K, Shibuya K, Aboyans, et al. Global and regional mortality from 235 causes of death for 20 age groups in 1990 and 2010: a systematic analysis for the Global Burden of Disease Study 2010. Lancet. 2012;380:2095-128.

9. Boschi-Pinto C, Velebit L, Shibuya K. Estimating child mortality due to diarrhoea in developing countries. Bull World Health Organ. 2008:86:710-7.

10. Guerrant RL, DeBoer MD, Moore SR, Scharf RJ, Lima AAM. The impoverished gut-a triple burden of diarrhoea, stunting and chronic disease. Nat Rev Gastroenterol Hepatol. 2013;10:220-9.

11. Ferriman A. BMJ readers choose the "sanitary revolution" as greatest medical advance since 1840. BMJ. 2007;334:111.

12. Esrey $S A$, Potash $J B$, Roberts $L$, Shiff $C$. Effects of improved water supply and sanitation on ascariasis, diarrhoea, dracunculiasis, hookworm infection, schistosomiasis, and trachoma. Bull World Health Organ. 1991;69:609-21.

13. Wolf J, Prüss-Ustün A, Cumming O, Bartram J, Bonjour S, Cairncross S, et al. Assessing the impact of drinking water and sanitation on diarrhoeal disease in low- and middle-income settings: systematic review and meta-regression. Trop Med Int Health. 2014;19(8):928-42.

14. Clasen TF, Bostoen K, Schmidt WP, Boisson S, Fung IC, Jenkins MW, et al. Interventions to improve disposal of human excreta for preventing diarrhoea. Cochrane Database Syst Rev. 2010;6:CD007180.

15. Engell RE, Lim SS. Does clean water matter? An updated analysis of water supply and sanitation interventions and diarrhoeal diseases. Lancet. 2013;381:544.

16. Bhutta ZA, Hafeez A, Rizvi A, Ali N, Khan A, Ahmad F, et al. Reproductive, maternal, newborn, and child health in Pakistan: challenges and opportunities. Lancet. 2013;381:2207-18

17. Bhutta ZA, Gazdar H, Haddad L. Seeing the unseen: breaking the logjam of undernutrition in Pakistan. Ids Bull I Dev Stud. 2013:44:1-9.

18. Bhutta ZA, Gupta I, de'Silva H, Manandhar D, Awasthi S, Hossain SMM. Maternal and child health: is South Asia ready for change? BMJ. 2004;328:816-9.

19. National Nutrition Survey 2011. Planning Commission, Planning \& Development Division, Government of Pakistan. 2011.

20. Sindh Bureau of Statistics and UNICEF; Sindh Multiple Indicator Cluster Survey 2014, Final Report. Karachi: Sindh Bureau of Statistics and UNICEF; 2015.

21. Gorstein J, Sullivan KM, Parvanta I, Begin F. Indicators and methods for cross-sectional surveys of vitamin and mineral status of populations. The Micronutrient Initiative (Ottawa) and the Centers for Disease Control and Prevention (Atlanta). 2007.

22. World Health Organization. WHO child growth standards: length/height-forage, weight-for-age, weight for- length, weight-for-height and body mass index-forage: methods and development. Geneva. 2006.

23. Gwatkin DR, Rutstein S, Johnson K, Pande R, Wagstaff A. Socio-economic differences in health, nutrition, and population. Washington: World Bank; 2000.

24. Wamani $\mathrm{H}$, Astrom AN, Peterson S, Tumwine JK, Tylleskar T. Boys are more stunted than girls in sub-Saharan Africa: a meta-analysis of 16 demographic and health surveys. BMC Pediatr. 2007;7:17.

25. Novignon J, Aboagye E, Agyemang OS, Aryeetey G. Socioeconomic-related inequalities in child malnutrition: evidence from the Ghana multiple indicator cluster survey. Health Econ Rev. 2015;5:34.
26. Van Den B, Ettyang GB, Keino S, Plasqui G. Determinants of stunting and overweight among young children and adolescents in sub-Saharan Africa. Food Nutr Bull. 2014;35:167-78.

27. Hong R. Effect of economic inequality on chronic childhood undernutrition in Ghana. Public Health Nutr. 2007;10:371-8.

28. Fotso JC. Child health inequities in developing countries: differences across urban and rural areas. Int J Equity Health. 2006;5:9.

29. Fotso JC. Urban-rural differentials in child malnutrition: trends and socioeconomic correlates in sub-Saharan Africa. Health Place. 2007:13:205-23.

30. Kumar A, Kumari D. Decomposing the Rural-urban Differentials in Childhood Malnutrition in India, 1992-2006. Asian Popul Stud. 2014;10:144-62.

31. Kismul, et al. The social context of severe child malnutrition: a qualitative household case study from a rural area of the Democratic Republic of Congo International. J Equity Health. 2015;14:47.

32. Disha A, Kuntal KS, Phuong HN, Michael TD, Marie TR, Purnima M, et al. Household food insecurity is associated with higher child undernutrition in Bangladesh, Ethiopia, and Vietnam, but the effect is not mediated by child dietary diversity. J Nutr. 2013;143:2015-21.

33. McDonald CM, McLean J, Kroeun H, Talukder A, Lynd LD, Green TJ. Household food insecurity and dietary diversity as correlates of maternal and child undernutrition in rural Cambodia. Eur J Clin Nutr. 2015;69(2):242-6.

\section{Submit your next manuscript to BioMed Central and we will help you at every step:}

- We accept pre-submission inquiries

- Our selector tool helps you to find the most relevant journal

- We provide round the clock customer support

- Convenient online submission

- Thorough peer review

- Inclusion in PubMed and all major indexing services

- Maximum visibility for your research

Submit your manuscript at www.biomedcentral.com/submit
) Biomed Central 